\title{
Medication labeling practices at in-patient hospital pharmacies: the present dilemma in Pakistan
}

\begin{abstract}
Drug labels provide first hand information to the patients as well as it provides a unique identity to the medical product. Misreading the label, inadequate information on label, inappropriate labeling font, writing style and its placement on the dosage form are the few of the barriers identified for inappropriate labeling practices.
\end{abstract}

Objective: The main objective of the present study was to assess current labeling practices in inpatient departments of health care facilities among public and private sectors in twin cities of Pakistan.

Methodology: A descriptive cross-sectional study design was used. A total of twenty healthcare facilities were randomly selected i.e. 10 from public and 10 from private sectors. As per WHO criteria thirty encounters per facility were observed. ISMP guidelines were used to develop a structured observation form. After data collection, data was recorded on structured observation form containing pre-determined set of indicators. After data collection, data was cleaned, coded and entered in SPSS version 21. Descriptive statistics of frequency and percentages were calculated. KruskalWallis and Mann-Whitney tests $(\mathrm{p} \leq 0.05)$ were performed to find out differences among variables.

Results: Out of total hospitals visited only $10 \%$ were having proper IPD pharmacy setup in public sector while in private sector $50 \%$ were having proper IPD pharmacy setup. Significant differences ( $\mathrm{p} \leq 0.05)$ were found among the labeling practices carried for label identification, label instruction and label layout with respect to city, sector, gender, designation, age, experience and dosage form. Labeling practices carried in private sector and healthcare facilities located in Islamabad were comparatively better than the public sector and healthcare facilities located in Rawalpindi. Pharmacists had relatively more compliance with the standard labeling guidelines.

Conclusion: The present study concluded that the labeling practices carried at the hospital pharmacies were not up to the mark. Although labeling practices in terms of labeling identification was appropriately mentioned but labeling instructions and layout were not in compliance with the standard labeling guidelines. This might be due to lack of availability/implementation of national standard labeling guidelines, lack of interest, knowledge and training of dispensers regarding good labeling practices.
Volume 2 Issue I - 2018

\author{
Madeeha Malik, Azhar Hussain, Tunzeela Amin \\ Hamdard Institute of Pharmaceutical Sciences, Hamdard \\ University, Pakistan
}

Correspondence: Madeeha Malik, Hamdard Institute of Pharmaceutical Sciences, Hamdard University, Islamabad Pakistan, Email madeehamalikI5@gmail.com

Received: July 30, 2017 | Published: January 23, 2018

Keywords: medicines, labeling, dispensers, IPD pharmacy, dispensers

\section{Introduction}

Dispensing process involves preparation and giving of medicines according to a prescription to a person, it also involves proper preparation and labeling of medicines for patient according to the instructions of prescriber. ${ }^{1}$ Dispensing is crucial process for assuring rational use of drugs as a small mistake can lead to wrong drug, wrong dose, wrong advice, therefore it is important that drug should be dispensed correctly. ${ }^{2}$ Many factors influence dispenser behavior including: training and knowledge, professional compensation, economic incentives, supply, available product information, availability of dispensing equipment, public versus private-sector promotional and marketing techniques, social status of a dispenser and his or her role in the health care system, dispenser-prescriber relationship and lack of communication skills. ${ }^{3}$ The pharmacists and other health personnel always try to reduce the chances of medication errors. It is the practice of labeling that helps them achieve this goal. ${ }^{4}$ Labeling is a unique identity or name given to a medicine so that patients can identify the medicine and find it easier to use. ${ }^{5}$ A properly labeled medicine not only helps the practitioner in prescribing correct medicine and nurses to administer right medicines in right doses to right patients but it also helps the patients to make informed decision in emergency situation..$^{6-7}$ Each type of drug dispensed i.e. OTC, controlled preparations and injections have their own labeling requirements that must be taken care during dispensing. This way the labeling will become adequate and the patient and practitioner both will be at benefit. ${ }^{8}$ Despite of the importance of medicine labeling, the labeling done in actual is very inconsistent and incomplete, ${ }^{9-10}$ as health personnel are not able to understand the signs, colors and dosages labeled of the packages. The reason for the high rate of medication errors even for the labeled medicinal drugs is that the labeling is ineffective. ${ }^{11}$ Owing to the importance of labeling of medicines different countries have developed their own guidelines. With respect to Pakistan un-availability of national standard labeling guidelines, lack of access to guidelines, lack of implementation, inadequate knowledge, training of dispensers, use of variable format of labeling among and within pharmacies, use of non-scientific and vague language on labels, improper use of auxiliary labels are the most 
common factors contributing towards dispensing errors. Although laws do exist in Pakistan regarding labeling of medicines but there is no national data base at present is available. There is strong need to recognize global standards of promoting Safe and efficient dispensing process..$^{12}$ Therefore, present study has been designed to assess current labeling practices of dispensed medicines at hospital pharmacies located in different health care facilities in twin cities of Pakistan.

\section{Methodology}

Study design: A descriptive cross-sectional study design was used to assess the labeling practices in twin cities of Pakistan. National bioethical committee is present for this type of research and it states that only institutional head approval is required for this type of study. Beside this approval was obtained for the study from the Ethical Committee of Hamdard University (Ref 638). Moreover any endorsement from Ministry of Health is not pre-requisite for questionnaire based studies in Pakistan. Despite that, prior information was sent to the Ministry of Health, Government of Pakistan. Approval was also taken from respective authorities of different healthcare facilities from which data has been collected. Besides this, respondents were ensured for the confidentiality of information.

Study population, sample size and sampling of respondents: In this study in-patient department pharmacies of twenty health facilities were visited, ten each from public and private sector in twin cities of Pakistan. Labeling practices from out-patient department pharmacies of hospitals were excluded. Ten of the total health care facilities were located in Rawalpindi and 10 of them were located in Islamabad. With respect to sector 5 healthcare facilities from public and 5 from private sector from each city were included. A total of 600 structured observation forms were filled. As per WHO, 30 encounters at each health facility were observed during study. Convenient sampling technique was adopted to select the encounter recorded at the study units that happen to be available at the time of data collection .

Study tool: A structured observation form was developed through extensive review of the literature and by using ISMP guidelines for medication label design as reference. The tool is divided into four major sections. Section I includes demographic data. Section II include parameters regarding label identification including name of person to whom medicine to be administered, name of drug dispensed, ingredients mentioned on the label (in case of compounded preparation), date of dispensing and initials of pharmacist and name of pharmacy/contact no/address. Section 3 includes parameters regarding label instructions including Unit dose, frequency of administration and volume (total quantity), duration of treatment on dispensed medicine envelop/packages: (if applicable) /Exp. date in case of comp. preparation, directions /precautions relating to the use of product, use the phrase "for external use" (where necessary), the words "keep out of the reach of children "or words of direction bearing a similar meaning and storage conditions of a product. Section 4 includes parameters regarding label layout including size, font, media used and placement of label. Responses were assigned as $1=$ yes/correct and $2=$ no/incorrect. The composite score range for label deification was ${ }^{6-12}$ label instructions ${ }^{7-14}$ and label layout. Lower score indicated better compliance with labeling guidelines. Face and content validity of the tool has been conducted by the supervisor and panel of experts. Pilot testing was conducted to confirm the reliability and internal consistency of the structured observation form before final execution of the study. Cranach Alpha value for the tool was 0.92 .
Data collection and analysis: Data was collected by the principal investigator trained by the supervisor by using structured observation method in which investigator observes 30 encounters for each healthcare facility. Data was collected from August to October 2015. After data collection, data was recorded on structured observation form containing pre-determined set of indicators. After data collection, data was cleaned, coded and entered in SPSS version 16. Descriptive statistics of frequency and percentages were calculated. KruskalWallis and Mann-Whitney tests $(\mathrm{p} \leq 0.05)$ were performed to find out differences among variables.

\section{Results}

\section{Demographic characteristics}

Out of total hospitals visited only $10 \%(\mathrm{n}=1)$ were having proper IPD pharmacy setup in public sector while in private sector $50 \%(\mathrm{n}=5)$ were having proper IPD pharmacy setup. In terms of dispensers, $20.83 \%(n=125)$ were pharmacists, $28.33 \%(n=170)$ of them were pharmacy technicians (having no pharmacy diploma as dispenser), $2.83 \%(n=17)$ were pharmacy assistant and $48 \%(n=288)$ were working as pharmacy technicians having pharmacy diploma (Table 1).

\section{Assessment of label identification for medicines dispensed at ipd pharmacy located in public and private healthcare facilities}

The correct labeling practices in terms of label identification at public sector healthcare facilities were: name of patient $(n=17$, $5.67 \%)$, name of drug $(\mathrm{n}=17,5.67 \%)$ and name of pharmacy and date of dispensing $(n=17,5.67 \%)$. On the other hand, in private sector the correct labeling practices carried in terms of label identification were: name of patient $(\mathrm{n}=208,69.33 \%)$, name of drug $(n=191,63.67 \%)$, ingredients $(n=24,8 \%)$, medicines having initials of pharmacist( $\mathrm{n}=112,37.33 \%$ ) ,name of pharmacy was mentioned $(\mathrm{n}=135,45 \%)$ and medicines labeled with date of dispensing $(\mathrm{n}=165$, $55 \%$ ). A detailed description is given (Table 2).

\section{Assessment of label instructions for medicines dispensed at ipd pharmacy located in public and private healthcare facilities}

The correct labeling practices in terms of label instructions at private sector healthcare facilities were: frequency $(n=114,38 \%)$, duration of treatment $(n=24,8 \%)$, directions/precautions $(n=59$, $19.67 \%)$, the phrase "for external use "was written $(n=12,4 \%)$, storage conditions $(\mathrm{n}=26,8.6 \%)$ and unit dose $(\mathrm{n}=76,25.33 \%)$. A detailed description is given (Table 3 ).

\section{Assessment of label layout for medicines dispensed at ipd pharmacy located in private and public healthcare facilities}

The correct labeling practices in terms of label layout at private sector healthcare facilities were: appropriate label size $(n=134$, $44.67 \%)$, readable label font $(\mathrm{n}=123,41 \%)$, printed media used for label $(n=78,26 \%)$ and appropriate placement of label $(n=134$, $44.67 \%$ ). A detailed description is given (Table 4).

\section{Comparison of labeling practice scores by demographic characteristics}

Significant differences $(\mathrm{p} \leq 0.05)$ were observed among the labeling practices carried for label identification, label instruction 
and label layout with respect to city, sector, gender, designation, age, experience and dosage form. Labeling practices carried in private sector healthcare facilities located in Islamabad were comparatively complying more to labeling guidelines. Dispensers in the age group of 20-30 years and having less than one year experience were relatively complying more with the standard labeling guidelines. Moreover, female dispensers and pharmacists were relatively better in terms of labeling practices. Furthermore, labeling practice carried for extemporaneous preparations were significantly more compliant to the standards (Table 5).

Table I Demographic characteristics

\begin{tabular}{|c|c|c|c|c|c|c|c|}
\hline \multirow{2}{*}{ Indicator } & \multirow{2}{*}{ Organization name } & \multicolumn{2}{|c|}{ Islamabad n(\%) } & \multicolumn{2}{|c|}{ Rawalpindi n(\%) } & \multicolumn{2}{|l|}{ Total n (\%) } \\
\hline & & Public & Private & Public & Private & Public & Private \\
\hline \multirow{2}{*}{ Department } & Proper IPD pharmacy setup & $1(20)$ & $5(100)$ & 0 & 0 & $1(10)$ & $5(50)$ \\
\hline & No proper IPD pharmacy setup & $4(80)$ & 0 & $5(100)$ & $5(100)$ & $9(90)$ & $5(50)$ \\
\hline \multirow{4}{*}{ Dispenser } & Pharmacist & 0 & $92(61.33)$ & $8(5.33)$ & $25(16.67)$ & $8(2.67)$ & $117(39)$ \\
\hline & Technician (without diploma) & $25(16.67)$ & $34(22.67)$ & $75(50)$ & $36(24)$ & $100(33.33)$ & $70(23.33)$ \\
\hline & Pharmacy assistant & $17(11.33)$ & 0 & 0 & 0 & $17(5.67)$ & 0 \\
\hline & Technician (Diploma holder) & $108(72)$ & $24(16)$ & $\begin{array}{l}67 \\
(44.67)\end{array}$ & $80(53.33)$ & $175(58.33)$ & $113(37.67)$ \\
\hline \multirow{2}{*}{ Gender } & Male & $150(100)$ & $81(54)$ & $\begin{array}{l}150 \\
(100)\end{array}$ & $130(86.67)$ & $300(100)$ & $211(70.33)$ \\
\hline & Female & 0 & $69(46)$ & 0 & $20(13.33)$ & & $89(29.67)$ \\
\hline \multirow{4}{*}{ Age } & 20-30 Years & 0 & $119(79.33)$ & $1(0.67)$ & $72(48)$ & $1(0.33)$ & $191(63.67)$ \\
\hline & $31-40$ Years & $88(58.67)$ & $31(20.67)$ & $\begin{array}{l}113 \\
(75.33)\end{array}$ & $78(52)$ & $201(67)$ & $109(36.33)$ \\
\hline & 41-50 Years & $62(41.33)$ & 0 & $36(24)$ & 0 & $98(32.67)$ & 0 \\
\hline & $>50$ Years & 0 & 0 & 0 & 0 & 0 & 0 \\
\hline \multirow{4}{*}{ Experience } & $<1$ Years & 0 & $6(4)$ & 0 & $1(0.67)$ & 0 & $7(2.33)$ \\
\hline & 1-5 Years & $5(3.33)$ & $81(54)$ & 0 & $49(32.67)$ & $5(1.67)$ & $130(43.33)$ \\
\hline & 6-10 Years & $55(36.67)$ & $56(37.33)$ & $102(68)$ & $85(56.67)$ & $157(52.33)$ & $141(47)$ \\
\hline & $>10$ Years & $90(60)$ & $7(4.66)$ & $48(32)$ & $15(10)$ & $138(46)$ & $22(7.33)$ \\
\hline \multirow{4}{*}{ Dispensing type } & Topical preparation & $14(9.33)$ & $6(4)$ & $13(8.67)$ & $10(6.67)$ & $27(9)$ & $16(5.33)$ \\
\hline & Extemporaneous preparation & 0 & $25(16.67)$ & 0 & $2(1.33)$ & 0 & $27(9)$ \\
\hline & Oral preparation & $55(36.67)$ & $43(28.67)$ & $36(24)$ & $56(37.33)$ & $91(30.33)$ & $99(33)$ \\
\hline & Inject able & $81(54)$ & $76(50.67)$ & $\begin{array}{l}101 \\
(67.33)\end{array}$ & $82(54.67)$ & $182(60.67)$ & $158(52.67)$ \\
\hline
\end{tabular}

Table 2 Assessment of label identification for medicines dispensed at IPD pharmacy located in public and private healthcare facilities

\begin{tabular}{|c|c|c|c|c|c|c|}
\hline \multirow{2}{*}{ Indicators } & \multicolumn{3}{|c|}{ Public n (\%) } & \multicolumn{3}{|l|}{ Private n (\%) } \\
\hline & $\begin{array}{l}\text { Correct } \\
\text { labeling }\end{array}$ & $\begin{array}{l}\text { Incorrect } \\
\text { labeling }\end{array}$ & $\begin{array}{l}\text { Not } \\
\text { applicable }\end{array}$ & Correct labeling & $\begin{array}{l}\text { Incorrect } \\
\text { labeling }\end{array}$ & Not applicable \\
\hline $\begin{array}{l}\text { Name of person to whom medicine } \\
\text { to be administered }\end{array}$ & $17(5.67)$ & $283(94.33)$ & 0 & $208(69.33)$ & $92(30.67)$ & 0 \\
\hline Name of drug & $17(5.67)$ & 283(94.33) & 0 & 191(63.67) & $109(36.33)$ & 0 \\
\hline Ingredients mentioned on label & 0 & 0 & $300(100)$ & $24(8)$ & $5(1.67)$ & $271(90.33)$ \\
\hline Initials of pharmacist & 0 & $300(100)$ & 0 & $112(37.33)$ & $188(62.67)$ & 0 \\
\hline Name of Pharmacy & $17(5.67)$ & 283(94.33) & 0 & $135(45)$ & $165(55)$ & 0 \\
\hline Date of Dispensing & $17(5.67)$ & 283(93.33) & 0 & $165(55)$ & $135(45)$ & 0 \\
\hline
\end{tabular}


TABLE 3 Assessment of label instructions for medicines dispensed at IPD pharmacy located in public and private healthcare facilities

\begin{tabular}{|c|c|c|c|c|c|c|}
\hline \multirow[b]{2}{*}{ Indicators } & \multicolumn{3}{|c|}{ Public n (\%) } & \multicolumn{3}{|c|}{ Private n (\%) } \\
\hline & $\begin{array}{l}\text { Correct } \\
\text { Labeling }\end{array}$ & $\begin{array}{l}\text { Incorrect } \\
\text { Labeling }\end{array}$ & $\begin{array}{l}\text { Not } \\
\text { Applicable }\end{array}$ & $\begin{array}{l}\text { Correct } \\
\text { Labeling }\end{array}$ & $\begin{array}{l}\text { Incorrect } \\
\text { Labeling }\end{array}$ & Not Applicable \\
\hline Unit dose & 0 & $300(100)$ & 0 & $76(25.33)$ & 192(64) & $32(10.67)$ \\
\hline $\begin{array}{l}\text { Frequency of administration and volume } \\
\text { (total quantity) }\end{array}$ & $16(5.33)$ & 284(94.67) & 0 & $114(38)$ & 184(61.33) & $2(0.67)$ \\
\hline $\begin{array}{l}\text { Duration of treatment on dispensed } \\
\text { medicine envelop/packages: (if } \\
\text { applicable) /Exp. date in case of comp. } \\
\text { Preparation }\end{array}$ & 0 & $24(8)$ & $276(92)$ & $24(8)$ & $29(9.67)$ & $247(82.33)$ \\
\hline $\begin{array}{l}\text { Directions / precautions relating to the use } \\
\text { of product }\end{array}$ & 0 & $300(100)$ & 0 & $59(19.67)$ & $239(79.67)$ & $2(0.67)$ \\
\hline $\begin{array}{l}\text { Use the phrase "for external use" (where } \\
\text { necessary) }\end{array}$ & 0 & $47(15.67)$ & $253(84.33)$ & $12(4)$ & $33(11)$ & $255(85)$ \\
\hline $\begin{array}{l}\text { The words "keep out of the reach of } \\
\text { children " or words of direction Bearing a } \\
\text { similar meaning }\end{array}$ & 0 & $300(100)$ & 0 & 0 & $300(100)$ & 0 \\
\hline Storage conditions of a product & 0 & $21(7)$ & 279(93) & $26(8.6)$ & $36(12)$ & $238(79.33)$ \\
\hline
\end{tabular}

All indicators may not be applicable for all dosage forms.

Table 4 Assessment of label layout for medicines dispensed at IPD pharmacy located in private and public healthcare facilities

\begin{tabular}{llll}
\hline Indicators & & Public n (\%) & Private n (\%) \\
Label size & Appropriate & 0 & $134(44.67)$ \\
& In-appropriate & $17(5.67)$ & $31(10.33)$ \\
& Not Applicable & $283(94.33)$ & $134(44.67)$ \\
& Readable & $17(5.67)$ & $123(41)$ \\
Font & Non-readable & 0 & $33(11)$ \\
& Not Applicable & $283(94.33)$ & $147(49)$ \\
& Hand written & 0 & $31(10.33)$ \\
Media used & Printed & 0 & $78(26)$ \\
& Partially printed & $17(5.67)$ & $57(19)$ \\
& Not Applicable & $283(94.33)$ & $134(44.67)$ \\
& Appropriate & $2(1.33)$ & $134(44.67)$ \\
Placement of label & In-appropriate & $15(5)$ & $32(10.67)$ \\
& Not applicable & $283(94.33)$ & $134(44.67)$ \\
& All indicators may not be applicable for all dosage forms &
\end{tabular}


Table 5 Comparison of labeling practice scores by demographic characteristics

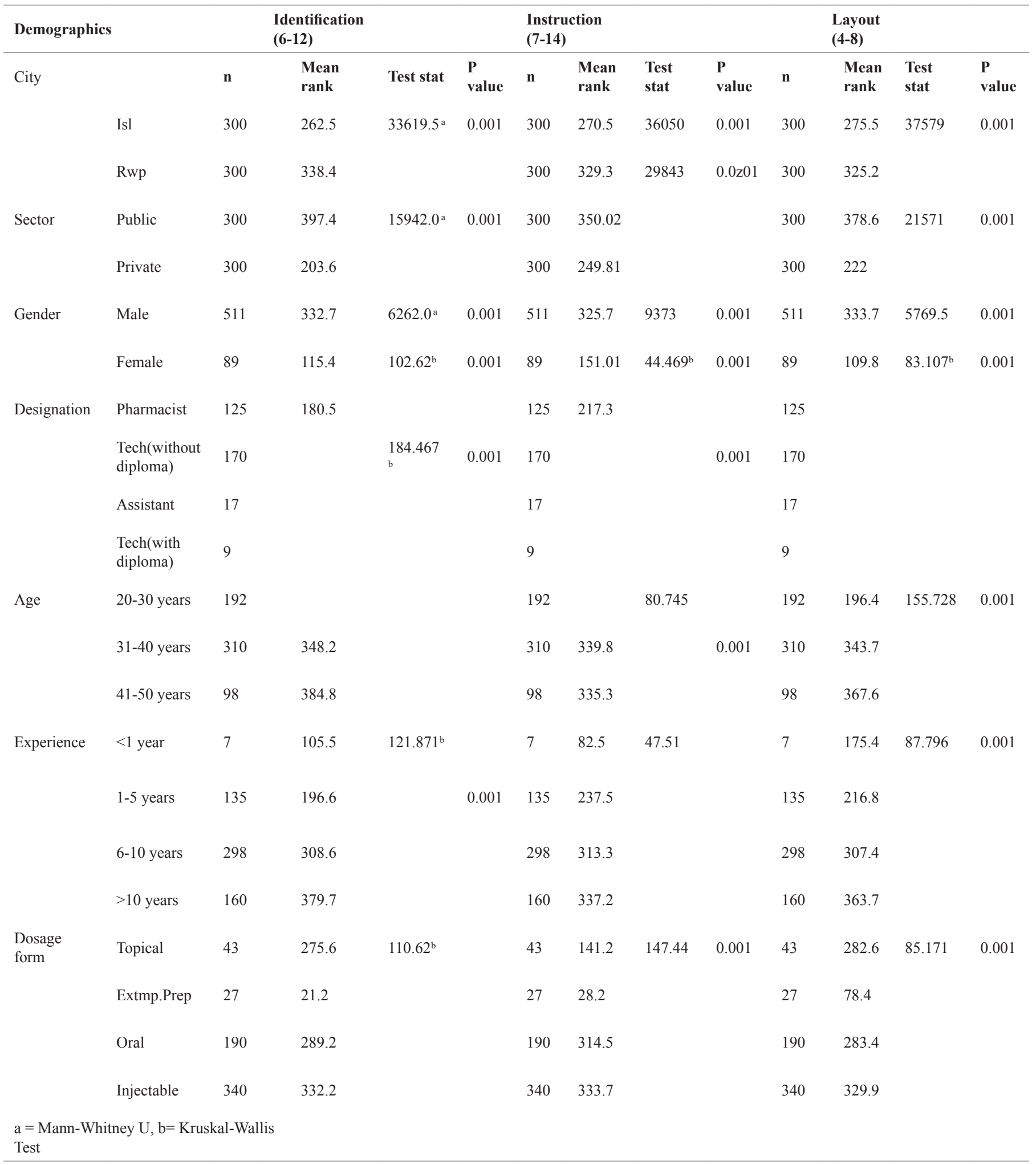




\section{Discussion}

Patient compliance and therapeutic success or failure of a medication depends upon the appropriate labeling. The findings of the current study reported poor labeling practice in the twin cities of Pakistan. Labeling practices carried out at hospital pharmacies located in private healthcare facilities were relatively better than at public hospital pharmacies. This difference may be due to the fact that the private hospitals are more concerned with the patient and attract the customers to enhance their market ranking. Similar results were reported from other studies conducted in India, Saudia Arabia and Ethopia. ${ }^{13-15}$ It is the duty of healthcare professionals to properly label the medications in order to provide patients better understanding of their treatment regimen. The results of the current study showed that label size and information on label was more accurate which were labeled by the pharmacist as compared to labeling practices by pharmacy technician or other dispenser. Indicators like unit dose, frequency and direction/precaution of usage were also more accurately labeled by the pharmacist than other dispensers. This might be due to the fact that pharmacists are the core person having better knowledge and training regarding any issue related to medicines and particularly dispensing of medicines. Similarly a study conducted in Turkey showed unsatisfactory dispensing practices by pharmacy staff as compared to pharmacists. ${ }^{16}$ Moreover, the results of the present study reported better labeling practices by dispensers aged between 20-30 years and having experience less than one year. Labeling information was more accurately mentioned by the female dispensers as compared to the male dispensers. These findings are in contrary with the findings reported by a study conducted in Ethopia which showed relatively better labeling practices by the male dispensers. ${ }^{17}$ On the other hand, the results of the present study showed that out of total samples observed, those of extemporaneous preparations were more accurately labeled. Their ingredients, name of persons, unit dose, direction and other related information was relatively labeled better as compared to oral and injectables. This might be due to the fact that it is almost impossible to identify the compounded preparation if it does not have any identity label on it. Moreover, its stability is effected, if date of manufacturing or dispensing is unknown. Similar results highlighting poor labeling practices for injectables were also reported by a study conducted in Canada. ${ }^{18}$ The findings of the current study further revealed that among the different standard indicators of labeling, ingredients, direction for use, person name to whom drug was dispensed were relatively more appropriately labeled rather than appropriate size of label, accurate label placement, font size of label, proper unit dose and frequency of administration, precautions related with use of medicines and auxiliary labels. Similar results were reported by studies conducted in United States and Australia. ${ }^{5,19}$

\section{Study limitations}

The present study was conducted in two cities of Pakistan and the results may not be generalizable to the whole country. The use of structured observation is an effective methodology for assessing practices but use of external data collectors can create biasness in the response of the dispensers.

\section{Conclusion}

The present study concluded that the labeling practices carried at the hospital pharmacies located in the twin cities were not up to the mark. Although labeling practices in terms of labeling identification was appropriately mentioned but labeling instructions and layout were not in compliance with the standard labeling guidelines. This might be due to lack of availability/implementation of national standard labeling guidelines, lack of interest, knowledge and training of dispensers regarding good labeling practices. However, pharmacists were relatively complying more with the standard labeling guidelines. All the stakeholders must work together to design and develop specific labeling guidelines for the medicines to be dispensed at any health care facility. The proper use of technology throughout the dispensing process can improve current situation and minimize medication errors. Proper training programs for dispensers (technical staff involved) can also help to minimize the labeling issues. Separate pharmacy setups for in-patients and outpatient departments can share work burden that can result in improved labeling practices in Pakistan.

\section{Acknowledgements}

None.

\section{Conflict of interest}

The author declares no conflict of interest.

\section{References}

1. World Health Organization. Quality assurance of pharmaceuticals: a compendium of guidelines and related materials. Good manufacturing practices and inspection USA; 2007.

2. Beardsley RS, Kimberlin CL, Tindall WN, et al. Communication skills in pharmacy practice: a practical guide for students and practitioners. Lippincott Williams \& Wilkins; 2012. 288 p.

3. Radyowijati A, Haak H. Improving antibiotic use in low-income countries: an overview of evidence on determinants. Social science \& medicine. 2003;57(4):733-744.

4. Shrank WH, ParkerR, Davis T, et al. Rationale and design of a randomized trial to evaluate an evidence-based prescription drug label on actual medication use. Contemporary clinical trials. 2010;31(6):564-571.

5. Lalor D. Medicines labelling. Australian Prescriber. 2011;34(5):35-40.

6. Karande S, Sankhe P, Kulkarni M. Patterns of prescription and drug dispensing. The Indian Journal of Pediatrics. 2005;72(2):117-121.

7. Kaufman SR. Verification of prescription information and warning label. US Patent 6: Script chek visual verification systems Inc; 2005.

8. Merry AF, Shipp DH, Lowinger JS. The contribution of labelling to safe medication administration in anaesthetic practice. Best Practice \& Research Clinical Anaesthesiology. 2011;25(2):145-159.

9. Shrank WH, Avorn J. Educating patients about their medications: the potential and limitations of written drug information. Health Aff Millwood. 2007;26(3):731-740.

10. Orser B. Reducing medication errors. Canadian Medical Association Journal. 2000;162(8):1150-1151.

11. Neoh CF, Hassali MA, Shafie AA, et al. Compliance towards dispensed medication labeling standards: a cross-sectional study in the state of Penang, Malaysia. Curr Drug Saf. 2009;(3):199-203.

12. Naveed S, Zafar IN, Musharraf M, et al. Pharmac y dispensing practice in various pharmacies of Karachi. Mintage Journal of pharmaceutical and medical sciences. 2014;3:19-21.

13. Admassie E, Begashaw B Hailu W. Assessment of drug Use practices and completeness of prescriptions in Gondar University teaching referral hospital. International Journal of Pharmaceutical Sciences and Research. 2013;4(1):265-275. 
14. Alkhani S, Ahmed Y, Bin-Sabbar N, et al. Current practices for labeling medications in hospitals in Riyadh, Saudi Arabia. Saudi Pharm J. 2013;21(4):345-349.

15. Nigussie WD. Assessment of the degree of adherence to health facility indicators related to rational drug use in selected health facilities of Amhara region, Northwest Ethiopia. Organization. 2014;5:4-10.

16. Toklu HZ. The pharmacy practice of community pharmacists in Turkey. Marmara Pharmaceutical Journal. 2010;14:53-60.
17. Lenjisa JL, Mosisa B, Woldu MA, et al. Analysis of dispensing practices at community pharmacy settings in Ambo Town, West Shewa, Ethiopia. Journal of Community Medicine \& Health Education. 2005;5:329.

18. Momtahan K, Burns CM, Jeon J, et al. Using human factors methods to evaluate the labelling of injectable drugs. Healthc Q. 2008;11(3):122-128.

19. Davis TC, Wolf MS, Bass PF, et al. Low literacy impairs comprehension of prescription drug warning labels. J Gen Intern Med. 2006;21(8):847-851. 